\title{
Chapter 11 \\ The Economic Effects of Equalizing the Effective Carbon Rate of Sectors: An Input-Output Analysis
}

\author{
Makoto Sugino
}

\begin{abstract}
The $2{ }^{\circ} \mathrm{C}$ target of the Paris Agreement has stimulated the implementation of carbon reducing policies such as carbon taxes and emission trading schemes, which explicitly applies a price on carbon emitting fuels. However, OECD (2016) reports that the effective carbon rate must be at least 30 Euros per ton of $\mathrm{CO}_{2}$. The effective carbon rate includes the implicit carbon price, e.g. energy taxes, along with the explicit carbon price. Previous studies have focused on the effects of explicit carbon prices. In this chapter, we will focus on the effective carbon rate and estimate the effects of carbon policies that increase the effective carbon rate to the 30 Euro threshold. We find that the short-term effect of a carbon tax that raises the effective carbon rate for all industries above 30 Euros will not only effect energy intensive industries, but also downstream industries that already have high effective carbon rates. Furthermore, we find that the carbon tax implemented in 2012 increase the average effective carbon rate, but increases the difference between taxed emitters and non-taxed emitters. Thus, tax exemption for energy intensive industries sacrifices economic efficiency.
\end{abstract}

Keywords Effective carbon rate $\cdot$ Input output analysis $\cdot$ Carbon tax $\cdot$ Cost containment measures $\cdot$ Energy tax $\cdot$ Tax exemption

\section{Introduction}

The emission of greenhouse gases (GHG) continued to increase even though the Kyoto protocol came into effect. The increase in emissions was due to global economic growth, which depends on fossil fuel usage, and voluntary emission reductions for developing countries. The $-2{ }^{\circ} \mathrm{C}$ target, however, requires global reductions of more than $50 \%$ compared to 1990 emission levels. The Paris agreement aims to

\footnotetext{
M. Sugino (凶)

Faculty of Humanities and Social Sciences, Yamagata University, Kojirakawa-machi 1-4-12,

Yamagata City, Yamagata 990-8560, Japan

e-mail: makoto.sug@gmail.com
} 
reduce GHG emissions globally, by stimulating emission reduction for all countries that have ratified the UNFCCC.

The countries that have signed the Paris agreement have been designing policies that would fadeout carbon usage. The main policy instrument discussed has been carbon pricing. A narrow definition of carbon pricing or explicit carbon pricing, refers to carbon taxes and emission trading schemes (ETS), which sets a price on carbon emissions. A broader definition of carbon pricing or implicit carbon pricing, includes energy taxes, feed-in tariffs and other indirect policies or instruments that effectively places a price on carbon.

Which definition of carbon pricing is important in reducing carbon emissions? To answer this question, the concept of effective carbon rate has recently been used. The effective carbon rate is the sum of taxes and tradable permits levied on carbon usage (OECD 2016). Taxes refers to energy taxes along with carbon taxes. Energy taxes are levied on energy based on volume, whereas carbon taxes are levied on energy based on their carbon content. Thus, feed-in tariffs are included in the calculation of the effective carbon rate.

Going back to the question above, the implicit carbon price is important in reducing emissions, because they give direct and indirect signals to consumers about the environmental damage caused by the use of carbon containing energy. On the other hand, the explicit carbon price is useful in comparing countries/regions having similar energy tax institutions.

Carbon Pricing Leadership Coalition (2017) suggests that the price on carbon needs to be at least $\$ 50$ to $\$ 100 / \mathrm{t}-\mathrm{CO}_{2}$ by 2030 to achieve the Paris climate goals. Similarly, OECD (2016) estimates that the minimum effective carbon rate of 30 Euros per ton of carbon dioxide emissions is needed to cover the damage caused by the emissions. However, OECD (2016) shows that the average effective carbon rate for $90 \%$ of emissions in 41 OECD and G20 countries is less than the minimum requirement.

OECD (2016) also shows that the effective carbon rate differs greatly within a country. The transport sector, in general, faces an extremely high effective carbon rate with $46 \%$ of emissions priced higher than 30 Euros per ton. On the other hand, other sectors face a low or no carbon price. For example, the manufacturing sector, which includes energy intensive trade exposed (EITE) industries, are often given special treatment because of the competitiveness and carbon leakage issues.

The carbon pricing gap, which is the percentage of emission without the 30 Euro carbon price, for Japan was $75 \%$ in 2012. In 2015, the percentage has gradually decreased to $69 \%$. Compared to EU counterparts, such as France, Germany and the United Kingdom, this percentage is 15-25\% higher (OECD 2018). This means that the Japanese economy does not pay enough for their carbon emissions, even though an economy-wide carbon tax was introduced in October 2012.

Why kind of economy-wide carbon tax was introduced in Japan starting from October 2012? The Japanese government introduced a carbon tax covering all carbon emitting energy usages at the rate of $¥ 96 / t-\mathrm{CO}_{2}$. The tax rate was scheduled to be raised to $¥ 192 / \mathrm{t}-\mathrm{CO}_{2}$ in April 2014 and reach $¥ 289 / \mathrm{t}-\mathrm{CO}_{2}$ in April 2016. The Japanese 
carbon tax can be consider to be an explicit carbon price because it is added on to the price of energy.

In March 2018, the Japanese Ministry of the Environment (MOEJ) published a report on the possibility of future carbon pricing policies in Japan. In this report, three options were presented to reduce $\mathrm{CO}_{2}$ emissions. The first option makes use of the economy-wide carbon tax introduced in 2012, by increasing the per ton carbon price. The second option is a mixture of emission trading scheme (ETS) and carbon tax. Under this option, large emitters will be regulated under the ETS while medium and small-sized emitters will be regulated by increasing the per ton carbon tax. The third option directly regulates each sector differently by setting individual targets. In other words, the first two options aim at increasing the effective carbon rate and reduce the carbon pricing gap.

The manufacturing industries, especially the EITE industries, have shown apprehension towards high carbon prices. The main discussion of high carbon prices is that the production costs will increase drastically, resulting in the loss of competitiveness in the global market (Arimura et al. 2019). As a consequence, domestic jobs related to manufacturing could be lost.

What will the short-term economic impact be if the effective carbon rate is raised to 30 Euros per ton $\mathrm{CO}_{2}$ ? To answer this question, we will test two hypothetical scenarios. The first scenario will assume that an economy-wide carbon tax of $¥ 289 / \mathrm{t}$ $\mathrm{CO}_{2}$ is implemented. This scenario will also assume that EITE industries are given special treatment to reduce the burden of the carbon tax. The second scenario will assume that an industry specific carbon tax is implemented to increase the effective carbon rate to the minimum of $¥ 4000 / \mathrm{t}-\mathrm{CO}_{2}$. ${ }^{1}$

\section{Existing Literature}

The short-run effect of carbon pricing (CP) has been analyzed in depth using inputoutput (I-O) models. In I-O models the effect of $\mathrm{CP}$ is analyzed by changing the value-added coefficients, because $\mathrm{CP}$ can be considered as indirect taxes, which is part of value added. The direct and indirect effect of CP are then calculated as increases in prices or costs.

Early research such as Sugimoto (1995) and Shimoda and Watanabe (2006) analyzed the impact of an upstream carbon tax using highly aggregated data. An upstream carbon tax is relatively easy to implement in Japan because more than 95\% of primary fuel are imported from abroad. They find that CP will increase prices of energy intensive industries more than their non-energy intensive industries counterparts.

Recent research focuses on downstream carbon taxes using detailed industrial classification data because they are consistent with the polluter pays principle (Morgenstern et al. 2004; Sugino et al. 2012; Sugino et al. 2013). In addition, the

\footnotetext{
${ }^{1}$ This price is equivalent to a 30 Euro/t- $\mathrm{CO}_{2}$ effective carbon price.
} 
downstream carbon taxes are more practical because the indirect emissions from electricity usage can be taxed properly to users of electricity, when the carbon taxes are implemented downstream. These studies have found that energy intensive industries have higher price or cost increases.

To understand the source of the price or cost increase, Morgenstern et al. (2004) and Sugino et al. (2013) decomposes the price increase into three components; direct emission, indirect emission and intermediate goods. The decomposition provides vital information on the source of the price increase. By determining the source of the cost increase, policy makers can introduce cost containment measures that effectively reduces the burden of carbon pricing policies. Their studies find that even though direct and indirect emissions are initially taxed, industries that use large quantities of intermediate goods also pays the burden of the tax. For example, the pig iron experiences high price increases because this industry uses coal and pays for the direct emissions. However, the crude steel (converters) industry uses large amounts of pig iron produced by the pig iron industry. Thus, the major source of the increase in price arises from intermediate goods.

Other research questions explored using I-O models concerning $\mathrm{CP}$ includes the burden on households in different regions and income classes (Shimoda and Watanabe 2006; Sugino et al. 2012), effect on GDP and employment (Nakamura and Kondo 2004; Sugino et al. 2013) and the effectiveness of cost containment measures (Chuo Kankyo Shingikai 2005; Sugino et al. 2013; Sato 2016).

These studies discussed above are similar in that they calculate the effect of a newly employed uniformed explicit CP. Energy related taxes, however, exists which differs among fuel types. Thus, the existing energy related taxes can be considered as a carbon tax with different per ton price. In this chapter, we will examine the effect of an explicit CP that differs between industries, which raises the effective carbon rate above 30 Euros. We will also estimate the effect of the carbon tax implemented in 2012 and compare the results using the I-O model.

\section{Energy Related Taxes}

Energy related taxes in Japan are imposed at the national and local level. At the national level there are six indirect taxes; gasoline tax, local gasoline tax, liquefied petroleum gas tax, aviation fuel tax, petroleum and coal tax and promotion of powerresources development tax. In addition, there is the light-oil delivery tax imposed as a local tax. Thus, there are 7 energy related taxes imposed in Japan along with the carbon tax as of January 2020.

The gasoline tax and local gasoline tax is imposed on gasoline at the rate of $¥ 48,600 / \mathrm{kL}$ and $¥ 5,200 / \mathrm{kL}$, respectively. Thus, gasoline is taxed a total of $¥ 53,800 / \mathrm{kL}$, which is equivalent to a $¥ 23,000 / \mathrm{t}-\mathrm{CO}_{2}$ carbon tax. The Liquefied petroleum gas tax is imposed on LPG at the rate of $¥ 17,500 / t$, whereas the aviation fuel tax is implemented on aviation fuel at the rate of $¥ 26,000 / \mathrm{kL}$. These four taxes are imposed on the transportation sector. 
Other than the taxes on transportation, the petroleum and coal tax is imposed upstream on crude oil, petroleum products, coal and LNG/LPG, when these fossil fuels are imported to Japan or extracted within Japan. The tax rates for crude oil, LNG/LPG and coal are $¥ 2,040 / \mathrm{kL}\left(¥ 780 / \mathrm{t}-\mathrm{CO}_{2}\right), ¥ 1,080 / \mathrm{t}\left(¥ 400 / \mathrm{t}-\mathrm{CO}_{2}\right)$ and $¥ 700 / \mathrm{t}$ ( $¥ 290 / \mathrm{t}-\mathrm{CO}_{2}$ ), respectively.

The final indirect tax on energy is the promotion of power-resources development tax which is imposed on the usage of electricity at the rate of $¥ 0.375 / \mathrm{kWh}$. This tax covers all economic agents that purchase electricity from the 10 major power companies in Japan, including self-consumption of power companies.

The light-oil delivery tax is imposed on light-oil (diesel fuel) because fuel taxes differs greatly between gasoline and diesel fuel. The tax rate is $¥ 32,100 / \mathrm{kL}$, which is equivalent to a $¥ 12,000 / \mathrm{t}-\mathrm{CO}_{2}$ carbon tax, that is less than the tax imposed on gasoline.

The energy related taxes in Japan puts a high carbon price on transportation fuels and a low carbon price for fuels used for electricity and the manufacturing industry. Thus, it can be anticipated that the effective carbon rate for the industrial sector is lower than the effective carbon rate, as reported in OECD (2016).

Other than the taxes discussed above the Japanese government implemented a carbon tax at the rate of $¥ 289 / \mathrm{t}-\mathrm{CO}_{2}$, which is added to the existing energy tax. The tax rate seems to be small compared to carbon taxes imposed in Europe. However, the coverage of the Japanese carbon tax is greater than $66 \%$ of total $\mathrm{CO}_{2}$ emissions. Thus, the carbon tax should increase the effective carbon rate of the entire Japanese economy.

The taxes discussed above are considered to raise costs for energy intensive industries. For example, the agriculture and fisheries sector use large amounts of light-oil, heavy oil and kerosene. Thus, production costs increase due to the taxes, in turn raising the prices of these products. As a countermeasure, tax exemptions and tax rebates are applied for those industries facing competitiveness issues and those who will suffer greatly due to the energy related taxes.

The petroleum and coal tax provide tax rebates for specific industries to ease the burden of the tax. For example, the coal for producing iron and steel, coal used to produce corks, coal used to produce cement and coal used to produce electricity in Okinawa prefecture are subject for tax rebates.

Similarly, the carbon tax implemented in 2012 also provides exemption and refund measures for the rates added by the carbon tax along with the petroleum and coal tax exemption for the following 5 cases.

1. Imported and domestic volatile oil for petrochemical products production

2. Imported specific coal

3. Specific coal for electric generation in Okinawa

4. Imported and domestic bunker A heavy oil for agriculture, forestry and fishery

5. Domestic oil asphalt.

In addition, the exemption and refund measures are provided only for the tax rates added by the carbon tax for the following 6 cases. 
1. Imported coal used for home generation of electricity for caustic soda production in caustic soda manufacturing industry

2. Heavy oil and light oil used for domestic cargo ships and passenger ships

3. Light oil used for railway

4. Aviation fuel for domestic flight

5. Imported coal used for home generation of electricity for salt production in salt manufacturing industry by the ion exchange membrane method

6. Light oil used for agriculture, forestry and fishery.

These countermeasures will lower the effective carbon rate. From the economic efficiency point of view, all economic agents should face the same effective carbon rate. Thus, the countermeasures provided by the government lowers economic efficiency of the energy related tax.

\section{Model and Data}

\subsection{Model}

The model used to estimate the increase in total cost due to CP applies the concept of embodied environmental burden emissions intensity discussed in Nansai and Moriguchi (2012). The embodied environmental burden emissions intensity uses the data provided by the input-output table and the emission intensity of each industry.

The embodied environmental burden emissions intensity is calculated by using the quantity determination model, which depicts the relationship between final demand and domestic production as,

$$
\mathbf{X}=(\mathbf{I}-\mathbf{A})^{-1} \mathbf{F}
$$

where $\mathbf{X}$ is the vector of total production, $\mathbf{I}$ is the identity matrix, $\mathbf{A}$ is the input coefficient matrix and $\mathbf{F}$ is the vector of final demand. The inverse matrix, $(\mathbf{I}-\mathbf{A})^{-1}$, is known as the Leontief inverse, which represents the amount of additional input that is required to produce an additional unit of output for each industry. The Leontief inverse is calibrated by using the figures in the input-output table. This model does not distinguish between domestic and imported goods. Thus, the additional domestic final demand will be satisfied by increases in domestic production, rather than importing goods from abroad to meet the additional domestic final demand.

Next, the Leontief inverse is used to estimate embodied environmental burden emissions intensity for each industry, $\mathbf{B}_{i}$ as,

$$
\mathbf{B}_{i}=\mathbf{E}(\mathbf{I}-\mathbf{A})^{-1} \mathbf{i}_{i}
$$

where $\mathbf{E}$ is the emission intensity vector and $\mathbf{i}_{i}$ is a unit vector where the component equals one for industry $i$ and zero otherwise. 
Using Eq. 2 and a carbon price $t$, the total cost due to the carbon price can be calculated as,

$$
\mathbf{C}_{i}=t \mathbf{E}(\mathbf{I}-\mathbf{A})^{-1} \mathbf{i}_{i}
$$

where, $\mathbf{C}_{i}$ is the total cost increase of industry $i$. Total cost increase calculated by using Eq. 3, includes direct and indirect effects of the implemented CP. Indirect effect refers to the indirect cost increase caused by the price increase in intermediate goods. The direct effect is the cost increase caused by the implementation of CP.

By changing the carbon price $t$, we can estimate the effect of a newly implemented tax on each industry by using Eq. 3. In the simulation, we will use a uniformed tax increase to depict the carbon tax implemented in 2012, while we use an industry specific carbon tax to raise the effective carbon rate above the $¥ 4000 / \mathrm{t}-\mathrm{CO}_{2}$ threshold. The details of the simulation scenario will be discussed in the next subsection.

\subsection{Simulation Scenario}

We will conduct two simulation scenarios; implementation of the carbon tax of $¥ 289 / \mathrm{t}-\mathrm{CO}_{2}$ and carbon pricing that increases the effective carbon rate over $¥ 4000 / \mathrm{t}$ $\mathrm{CO}_{2}$.

The first scenario examines the effect of the carbon tax implemented in 2012, which covers the entire Japanese economy. The cost containment measure will also be included in this scenario. Thus, the cost increase calculated will depict the cost increase associated with the implementation of the carbon tax of 2012.

The second simulation scenario is the case where all emitters are confronted by a new carbon tax with an ununiformed tax rate. In this scenario, emitters that presently face a high effective carbon rate will face a low newly implemented carbon tax. On the other hand, industries that have low effective carbon rates will be taxed heavily by the new carbon tax.

\subsection{Data}

The newest input-output table available is the 2015 Japanese national input-output table. However, we will make use of the 2011 Japanese national input-output table due to the following reason. The economy-wide carbon tax was introduced in 2012. If we use the 2015 data, we will need to accurately determine the payment of the carbon tax for each industry. If we use the 2011 data, then we do not need to calculate the additional carbon tax payment for each industry. In other words, the 2011 data does not include the effect of the carbon tax whereas the 2015 data will include the effect of the carbon tax. 
The Japanese national I-O table list more than 400 industries that produce over 500 products. When calculating the direct and indirect effects of the $\mathrm{CP}$, we need to aggregate the industries/products so that 1 industry produces 1 product, in other words we aggregate the data so that the matrix is a square matrix. The dimension of the square matrix for the 2011 data is 393 by 393. Of the 393 industries, 237 industries belong to the manufacturing industry.

Tax revenues are reported annually by the National Tax Agency in the "National Tax Agency Annual Statistics Report." In this report, energy related tax reported are (1) gasoline tax and local gasoline tax, (2) aviation fuel tax, (3) liquefied petroleum gas tax, (4) petroleum and coal tax and (5) promotion of power-resources development tax. ${ }^{2}$

One shortcoming of this data set is that the tax payments are not aggregated at the sector level. Thus, the tax payments of the entire economy can be observed, but not in detail. To overcome this shortcoming, we need to estimate the amount of energy related tax payments for the year 2011 .

The Japanese national I-O table provides the quantities of fossil fuels, electricity and other products purchased by each industry in the "Value and Quantity table." Using these values, we could estimate the $\mathrm{CO}_{2}$ emissions for each industry along with the energy related tax payment. However, it is known among researchers that the values for coal is inaccurate. To over come this problem, we make use of Nansai (2019). ${ }^{3}$

3EID estimates the amount of energy used along with the $\mathrm{CO}_{2}$ emitted by fuel type for industries listed in the 2011 Japanese national I-O table. Since the industrial classification is identical, we can estimate the amount of energy related tax payment for each industry with high accuracy. In addition, the tax system is very complex, as discussed in the previous section, to model precisely. We estimate the tax payment for each industry by using the emission data and fuel usage provided by 3EID because we can determine whether the emissions are taxed.

Direct emissions are calculated by using the information provided by 3EID, but we use the "Value and Quantity table" provided as supplementary data in the Japanese input-output table. We allocate the direct emissions from the electricity and private power generation to the industries that uses electricity produced by these two industries. Thus, we treat total emissions by each industry as the sum of direct and indirect emissions.

We will focus on the six indirect taxes (gasoline tax, local gasoline tax, liquefied petroleum gas tax, aviation fuel tax, petroleum and coal tax and promotion of powerresources development tax) and the carbon tax in our analysis.

\footnotetext{
${ }^{2}$ There are other energy related taxes imposed by the local authority. However, we will omit these local taxes in the simulation due to data restriction.

${ }^{3}$ Nansai (2019) is also refer to as 3EID which is the abbreviation of "Embodied Energy and Emission Intensity Data for Japan Using Input-Output Tables".
} 
Table 1 Effective carbon rate w/and w/o carbon $\operatorname{tax}\left(¥ / \mathrm{t}-\mathrm{CO}_{2}\right)$

\begin{tabular}{l|l|l}
\hline \multirow{2}{*}{ Sector } & \multicolumn{2}{|l}{ Effective carbon rate } \\
\cline { 2 - 3 } & w/o carbon tax & w/carbon tax \\
\hline Agriculture, forestry and fishery & 1,397 & 1,586 \\
\hline Mining & 867 & 1,152 \\
\hline Manufacturing & 411 & 594 \\
\hline Transportation & 6,798 & 6,985 \\
\hline Other sectors & 2,030 & 2,315 \\
\hline Households & 7,549 & 7,715 \\
\hline Total & 3,236 & 3,463 \\
\hline
\end{tabular}

\section{Results}

\subsection{Effective Carbon Rate}

The 3EID data reports that the total $\mathrm{CO}_{2}$ emission from combustion of fossil fuels was $1.235 \mathrm{Gt}-\mathrm{CO}_{2}$ for 2011 . Thus, if the minimum carbon price of $¥ 4,000 / \mathrm{t}-\mathrm{CO}_{2}$ is applied to all of Japan's $\mathrm{CO}_{2}$ emission, then the total tax revenue will be 4.942 trillion yen. The tax revenue in our model for 2011 is 3.996 trillion yen. ${ }^{4}$ This means that the present energy related tax falls short by $22 \%$ to reach the minimum threshold. The carbon tax implemented in October 2012 increases the total tax revenue to $¥ 4.269$ trillion, which is still $15 \%$ short of the minimum requirement.

The effective carbon rate for the entire Japanese economy is calculated to be $¥ 3,236 / t-\mathrm{CO}_{2}$, before the implementation of the carbon tax. The carbon tax raises the effective carbon rate to $¥ 3,457 / \mathrm{t}-\mathrm{CO}_{2}$ (Table 1 ). Thus, an additional tax of $¥ 543 / \mathrm{t}$ $\mathrm{CO}_{2}$ is need to reach $¥ 4000 / \mathrm{t}-\mathrm{CO}_{2}$. Therefore, this implies that the present energy related tax seems to be quite high.

The effective carbon rate for each sector, however, tells a different story. The effective carbon rate is $¥ 2,045 / \mathrm{t}-\mathrm{CO}_{2}$, if we exclude the energy related tax paid by households which is $¥ 7,549 / \mathrm{t}-\mathrm{CO}_{2}$ (Fig. 1). The household effective carbon rate raises to $¥ 7,715 / \mathrm{t}-\mathrm{CO}_{2}$ with the carbon tax. Thus, the household faces a higher effective carbon rate compared to other parts of the economy.

Looking at each individual sector we can observe that the effective carbon rate differs greatly. For example, the transportation sector faces an effective carbon rate of $¥ 6,798 / \mathrm{t}-\mathrm{CO}_{2}$ as of 2011 , which is higher than the minimum effective carbon rate. On the other hand, the manufacturing sector faces an effective carbon rate of only $¥ 411 / \mathrm{t}-\mathrm{CO}_{2}$. Thus, the difference in the effective carbon rate is more than 16 times. Furthermore, only the transportation sector and the households face more than the minimum effective carbon rate of $¥ 4,000 / \mathrm{t}-\mathrm{CO}_{2}$. This means that the prior

\footnotetext{
${ }^{4}$ The total tax revenue reported was 3.855 trillion yen, which is approximately $3.65 \%$ less than our model.
} 


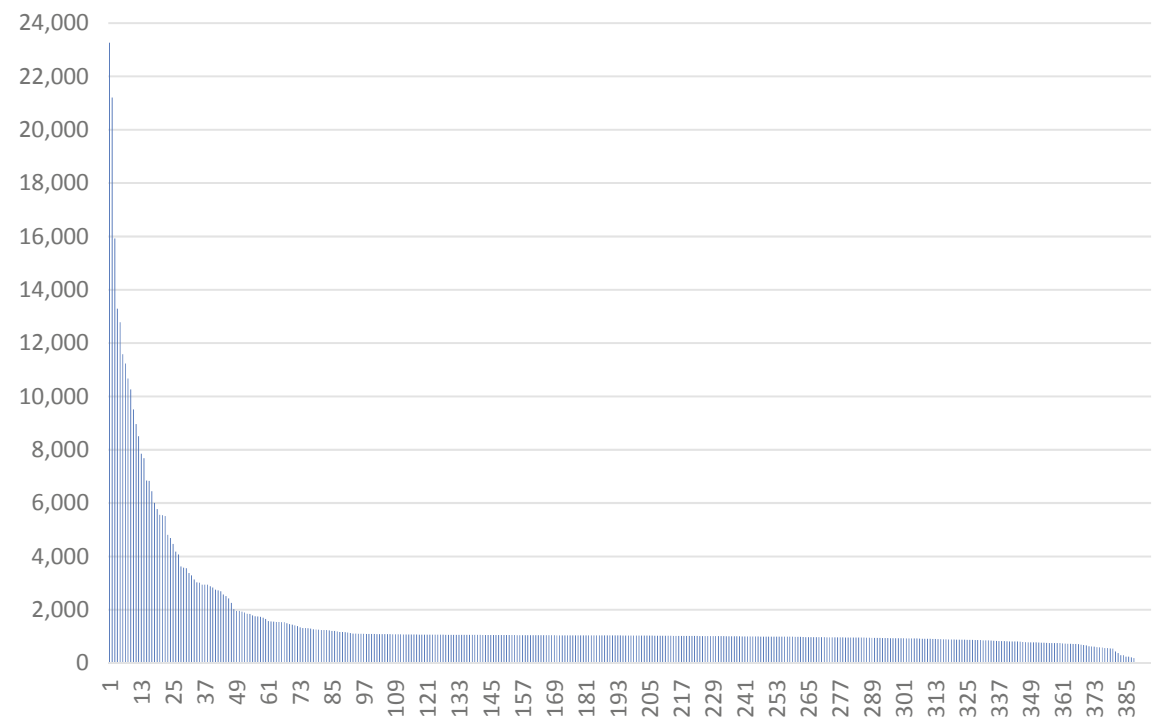

Fig. 1 Effective carbon rate by sector

to 2012, energy related taxes focuses on taxing transportation and heating rather than production activities.

The carbon tax implemented in 2012 increases the effective carbon rate for all sectors because the tax is imposed on $66 \%$ of Japan’s emissions at the rate of $¥ 289 / \mathrm{t}$ $\mathrm{CO}_{2}$. However, the difference between the top and bottom industry becomes $¥ 6,391 / \mathrm{t}$ $\mathrm{CO}_{2}$ from $¥ 6,387 / \mathrm{t}-\mathrm{CO}_{2}$. From the equity point of view, the carbon tax increases the inequality of the energy related tax burden. This is the result of the special treatment given to certain industries that faces the competitiveness issue.

What does the distribution of the effective carbon rate look like? Figure 1 shows the distribution of the effective carbon rate, including the carbon tax, for the entire Japanese economy. The vertical axis shows the effective carbon rate (yen per ton $\mathrm{CO}_{2}$ ) and the horizontal axis shows the number of industries. From the figure, only 27 sectors face an effective carbon rate over $¥ 4,000 / \mathrm{t}-\mathrm{CO}_{2}$ and 21 sectors with effective carbon rate between $¥ 3,000$ and $¥ 4,000 / \mathrm{t}-\mathrm{CO}_{2}$. On the other hand, 346 sectors out of 393 sectors ( $88 \%$ of the industries) face an effective carbon rate less than $¥ 2,000 / \mathrm{t}$ $\mathrm{CO}_{2}$, of which 154 sectors face effective carbon rates below $¥ 1,000 / \mathrm{t}-\mathrm{CO}_{2}$. This result confirms the findings reported in OECD (2016), which reported that only a fraction of sectors faces more than the minimum requirement, whereas most of the sectors face a low or no effective carbon rate. 


\subsection{Cost Increase Due to Carbon Tax (¥289/t-CO $\left.\mathrm{O}_{2}\right)$}

In the previous subsection, it was shown that the effective carbon rate differs greatly among industries. In this subsection, the effects of the carbon tax implemented in 2012 are presented.

The cost increases due to the implementation of the carbon tax of $¥ 289 / \mathrm{t}-\mathrm{CO}_{2}$ is shown in Table 2. The highest cost increase is estimated as $3.951 \%$ for electricity. Electricity is followed by compressed and liquified gas, self-transport (freight), selftransport (passengers) and road freight transport. The top 20 sectors include energy intensive industries that are not given special treatment towards competitiveness and leakage issues within the carbon tax.

The average cost increase, due to the $¥ 289 / \mathrm{t}-\mathrm{CO}_{2}$ carbon tax is $0.385 \%$. Thus, the cost increase for the top 20 industries ranges from 2 to 10 times the average cost increase. As for the energy intensive industries, such as pig iron and cement, the cost increase was estimated at $0.553 \%$ and $0.643 \%$, respectively. These two industries have cost increases above the average, implying that the special treatment

Table 2 Cost increase due to carbon tax (Top 20 sectors)

\begin{tabular}{l|l}
\hline Sector & Carbon tax (\%) \\
\hline Electricity & 3.951 \\
\hline Compressed gas and liquefied gas & 1.604 \\
\hline Self-transport (freight) & 1.471 \\
\hline Self-transport (passengers) & 1.427 \\
\hline $\begin{array}{l}\text { Road freight transport (except } \\
\text { self-transport) }\end{array}$ & 1.313 \\
\hline Petrochemical basic products & 1.271 \\
\hline Retail trade & 1.103 \\
\hline Aliphatic intermediates & 1.076 \\
\hline $\begin{array}{l}\text { Petroleum refinery products (including } \\
\text { greases) }\end{array}$ & 1.046 \\
\hline $\begin{array}{l}\text { Petrochemical aromatic products (except } \\
\text { synthetic resin) }\end{array}$ & 1.007 \\
\hline Cyclic intermediates & \\
\hline Wheat, barley and the like & 0.994 \\
\hline Crude steel (electric furnaces) & 0.952 \\
\hline Thermoplastics resins & 0.926 \\
\hline Industrial soda chemicals & 0.924 \\
\hline Lead and zinc (including regenerated lead) & 0.829 \\
\hline Synthetic fibers & 0.775 \\
\hline Plastic products & 0.755 \\
\hline Synthetic rubber & 0.747 \\
\hline Cold-finished steel & 0.742 \\
\hline & \\
\hline
\end{tabular}


for these industries does not completely exempt them from production cost increase. However, the cost increase calculated in Sugino et al. (2013) for pig iron showed that the expected cost increase was more than $30 \%$ when a $¥ 4,000 / \mathrm{t}-\mathrm{CO}_{2}$ carbon tax is implemented. Thus, the estimated cost increase without the special treatment will be approximately $2 \%$ using the results from Sugino et al. (2013). ${ }^{5}$ Therefore, a $0.553 \%$ increase is much lower than the $2 \%$ if there were no exemption program in the carbon tax.

The carbon tax scenario is not fictitious, because the Japanese government implemented the $¥ 289 / \mathrm{t}-\mathrm{CO}_{2}$ tax in 2012 . Thus, we can check if the cost increase calculated above was actually experienced.

The Agency for Natural Resources and Energy reports the average electricity price for household usage and industrial usage. The figures for the year 2011 were $¥ 21.3 / \mathrm{kWh}$ and $¥ 14.6 / \mathrm{kWh}$ for households and industry, respectively. These figures changed to $¥ 22.3 / \mathrm{kWh}$ and $¥ 15.7 / \mathrm{kWh}$ in 2012 , which is an increase of $4.7 \%$ and $7.5 \%$. These figures seem to indicate an increase higher than the estimated cost increase, but caution is needed in interpreting the figures. In other words, these figures, i.e., real electricity prices, includes the cost increase in inputs such as oil prices. In addition, eastern Japan experienced an earthquake of M9 on the Richter Scale in 2011, which lead to the meltdown of the nuclear power plant in Fukushima. After the earthquake, nuclear power plants were shut down and were substituted by carbon emitting power plants. Thus, the price increase between 2011 and 2012 may reflect these incidents. The carbon tax rate was raised twice between 2012 and 2016 from approximately $¥ 96 / \mathrm{t}-\mathrm{CO}_{2}$ to $¥ 289 / \mathrm{t}-\mathrm{CO}_{2}$, However, the electricity prices were $¥ 22.4 / \mathrm{kWh}$ and $¥ 15.6 / \mathrm{kWh}$ in 2016 . Thus, the change between 2012 and 2016 was - $¥ 0.1 / \mathrm{kWh}$ for both household and industrial usage. Fossil fuel prices during this period fell, which contributed in the fall in electricity prices.

The Bank of Japan database reports the prices of domestically traded products. The price increase for compressed gas and liquified gas between 2011 and 2016 was $3.5 \%$, whereas the price decreased for petrochemical basic products by $28 \%$ during the same time span. Thus, the cost increase calculated using the input output model is only a small aspect of the "real" price. The cost increase calculated here are not realized in the real world, because firms do not always pass through the carbon cost to consumers, because of the risk of losing the market share. Another reason why the estimated figures are not realized is because the model assumes that the technology is fixed. In reality, firms may invest in newer technology that are energy efficient, which may lower production costs even though the carbon tax is levied on fossil fuels.

\footnotetext{
${ }^{5}$ The cost increase calculated using the I-O model increases linearly with the carbon tax rate. Therefore, the results can be compared by adjusting the tax rate. In Sugino et al. (2013), the tax rate used was $¥ 4,000 / \mathrm{t}-\mathrm{CO}_{2}$. The estimated cost increase is calculated by multiplying $30 \%$ with $¥ 289 / \mathrm{t}-\mathrm{CO}_{2}$ and dividing by $¥ 4,000 / \mathrm{t}-\mathrm{CO}_{2}$, which is approximately $2 \%$.
} 


\subsection{Cost Increase Due to Increasing the Effective Carbon Rate}

What will the cost increase be if an industry specific carbon tax is implemented to raise the effective carbon rate to $¥ 4,000 / \mathrm{t}-\mathrm{CO}_{2}$ ? The cost increase for the top 20 industries, due to a tax that raises the effective carbon rate over $¥ 4,000 / \mathrm{t}-\mathrm{CO}_{2}$ is shown in Table 3. Pig iron is estimated to experience the highest cost increase of $40.383 \%$ when the effective carbon rate is raised to the minimum price. Other industries that are estimated to experience high cost increases is international shipping, crude steel (converters), hot rolled steel and cold-finished steel at 35.545\%, 29.996\%, $24.730 \%$ and $18.891 \%$, respectively.

Ten out of the twenty industries listed in Table 3 belong to the iron and steel industry. The high cost increase of the iron and steel reflects the indirect cost increase associated with the minimum effective carbon rate also shown in Sugino et al. (2013). These industries have high cost increases because their intermediate products are mainly from the pig iron industry, which will face a high carbon tax to meet the

Table 3 Cost increase due to effective CR (Top 20 sectors)

\begin{tabular}{l|l}
\hline Sector & Effective CR (\%) \\
\hline Pig iron & 40.383 \\
\hline International shipping & 35.545 \\
\hline Crude steel (converters) & 29.996 \\
\hline Hot rolled steel & 24.730 \\
\hline Cold-finished steel & 18.891 \\
\hline Petrochemical basic products & 17.370 \\
\hline Steel pipes and tubes & 16.019 \\
\hline $\begin{array}{l}\text { Petroleum refinery products (including } \\
\text { greases) }\end{array}$ & 15.891 \\
\hline Iron and steel shearing and slitting & 15.351 \\
\hline $\begin{array}{l}\text { Petrochemical aromatic products (except } \\
\text { synthetic resin) }\end{array}$ & 14.143 \\
\hline Coated steel & 13.836 \\
\hline Aliphatic intermediates & 12.763 \\
\hline Cast and forged materials (iron) & 12.703 \\
\hline Miscellaneous iron or steel products & 12.009 \\
\hline Cyclic intermediates & 11.940 \\
\hline $\begin{array}{l}\text { Road freight transport (except } \\
\text { self-transport) }\end{array}$ & 11.783 \\
\hline Thermoplastics resins & 11.142 \\
\hline Retail trade & 10.742 \\
\hline Coal products & 10.742 \\
\hline Metal products for construction & 10.193 \\
\hline & \\
\hline
\end{tabular}


minimum effective carbon rate, because they have been granted special treatment in existing energy related taxes.

The average cost increase in the minimum effective carbon rate scenario was $3.789 \%$. The pig iron and international shipping industry is more than ten times the average, meaning that these industries will suffer the most from the minimum effective carbon rate policy. Other industries listed in Table 3 have cost increases higher than two times the average.

The results above show that if the Japanese government chooses to implement a new tax or raises taxes to close the carbon pricing gap to zero, then EITE industries such as the iron and steel sector will experience a price increase ranging from $10 \%$ to $40 \%$. The cost increase has a possibility of deteriorating the competitiveness of EITE industries in the domestic and international market, if the cost increase due to the carbon price is increased to cover the minimum damage of $\mathrm{CO}_{2}$ emissions. Thus, the cost increase will not be acceptable or actions against the implementation of carbon prices may arise, at least in the short-run, where production processes are not adjustable.

What kind of options are available to lower the burden of carbon pricing for EITE industries to accept new carbon pricing schemes? One obvious option is the exclusion of EITE industries altogether from carbon pricing. This option, however, will reduce the economic efficiency of the carbon pricing scheme and shift the burden to other parts of the economy. The second option is the use of cost containment measures such as free allocation or output-based allocation discussed in Fischer and Fox (2007) and Takeda et al. (2014).

In the third phase of the EU-ETS, industries defined as EITE, can receive free allocation of emission permits. The free allocation of permits will lower compliance costs for EITE industries, resulting in lower product prices. Firms that receive free permits are not required to produce the same amount after implementation of the carbon price. Thus, firms may reduce the amount of production and sell the over allocated permits, which increases net profits of the firm.

To tackle this problem, in an output-based allocation (OBA) program, firms receive emission permits for free based on the amount of products produced. Thus, OBA will not lower the supply of goods produced as in the EU-ETS allocation regime.

In any case, cost containment measures may be needed in the short-run for firms to adjust to the expected cost increase brought by the carbon price. The cost containment measure will lower the effective carbon rate and increase the carbon pricing gap for the EITE industries. Policy makers will need to understand the tradeoffs associated with the cost containment measure and carefully plan the fading out of such measure to increase the effective carbon rate in the future. 
Table 4 Descriptive statistics of cost increase due to carbon tax and effective CR

\begin{tabular}{l|c|c}
\hline & Carbon tax & Effective CR \\
\hline Mean & $0.385 \%$ & $3.789 \%$ \\
\hline Median & $0.332 \%$ & $2.953 \%$ \\
\hline St. Dev & $0.279 \%$ & $4.007 \%$ \\
\hline Kurtosis & 70.022 & 34.052 \\
\hline Skewness & 6.291 & 4.999 \\
\hline Minimum & $0.027 \%$ & $0.206 \%$ \\
\hline Maximum & $3.951 \%$ & $40.383 \%$ \\
\hline
\end{tabular}

\subsection{Comparison of the Two Simulations}

The previous two sub-sections presented the results of the two simulation scenarios. In this sub-section we will compare the two simulation results.

Table 4 summarizes the descriptive statistics of the two simulation results. The average cost increase differs greatly for the two scenarios. The carbon tax scenario and effective carbon rate scenario differs by the order of magnitude. This is because the additional tax needs to raise the effective carbon rate is 10 times greater than the carbon tax implemented in 2012. Thus, the average cost increase is approximately 10 times greater for the effective carbon rate scenario.

Likewise, the minimum and maximum cost increase differs by the order of 10 . Thus, the effective carbon rate aims at increasing the burden equally by 10 times of the carbon tax.

The figures for kurtosis and skewness, shows that the distribution of the cost increase for both carbon tax and effective carbon rate will not be symmetric around the mean with fat tails. In other words, the distribution will be positively skewed and have a long tail to the right. The effective carbon rate, however, has a smaller value for skewness, meaning that the cost increases are more symmetric than the carbon tax. This result arises from the fact that the carbon tax gives special treatment to energy intensive industries, while the effective carbon rate taxes the energy intensive industries heavily because the present energy related tax lowers the effective carbon rate well below $¥ 4,000 / \mathrm{t}-\mathrm{CO}_{2}$.

What kind of energy tax reforms are need to meet the minimum effective carbon rate requirement? The present energy tax implemented in Japan, provides tax cuts and tax exemptions for industries that are highly affected by the energy tax, i.e., mainly EITE industries. If these measures are abolished, then the effective carbon rates are expected to rise. The minimum will not be met by taking away the tax cut/exemption. Therefore, further measures will be need to raise the effective carbon rate. One option will be the raise in tax rates for coal, because coal has the highest carbon content with the lowest tax rate in Japan. By raising the tax rate for coal, electricity and iron and steel prices are expected to raise because of their heavy use of coal. 
As Table 1 shows, the effective carbon rate for the manufacturing sector is approximately $¥ 600 / \mathrm{t}-\mathrm{CO}_{2}$ which falls short of the $¥ 4,000 / \mathrm{t}-\mathrm{CO}_{2}$ minimum. Another option is to raise the carbon tax rate or implement a cap-and-trade type emission trading scheme for the manufacturing sector. The former will raise the effective carbon rate of the transportation and household sector, which is already higher than the minimum. The latter, will raise the effective carbon rate for those that are subject to the emission trading scheme. Thus, only the effective carbon rate of the manufacturing sector is affected. The latter seems to be a better choice from the perspective of equality, but from a political perspective the former seems to be the better choice.

\section{Conclusion}

The results of the two simulation scenarios show that the cost increase of industries will differ greatly. The carbon tax will increase the cost for the non-energy intensive industries more that their energy intensive counterparts. On the other hand, the effective carbon rate scenario will increase the cost of energy intensive industries, because these industries are excluded from the energy related taxes including the carbon tax.

If a new tax which raises the effective carbon rate above the $¥ 4,000 \mathrm{t} / \mathrm{CO}_{2}$ threshold is implemented, then the energy related industries will experience high production costs. Thus, these industries may resist or lobby against the implementation of an industry specific carbon tax. For example, the iron and steel industry will suffer the most if the effective carbon rate gap is filled by the new carbon tax, because the iron and steel sector is responsible for approximately a quarter of direct emissions in Japan.

Caution is needed in interpreting the results for the cost increase. First, the cost increase estimated can be consider as the upper estimate of the carbon tax. The I-O model assumes a Leontief production function where the input requirements cannot be adjusted, at least in the short-run. This assumption will increase the cost of production because firms are unable to adjust their inputs to cheaper substitutes or install new and efficient technology. Furthermore, the I-O model assumes that the increase in costs are $100 \%$ passed through to the products. Some industries, however, may not be able to pass the increased cost through because the demand for their products could be elastic. Thus, if they passed the increased cost through to their products, the demand will drop significantly, leading to drops in market shares home and abroad. These industries may not increase the price even though the production cost is levied, by reducing profits or jobs. In addition, as discussed in Sect. 4.2, the actual cost increase in production is affected by other aspects other than carbon pricing, such as fuel prices and mineral prices.

Secondly, the cost increase calculated using the I-O model assumes that the tax revenues are not redistributed or used to increase government expenditure. If the tax revenue from $\mathrm{CO}_{2}$ emission is used to reduce corporate taxes, social security payments or other taxes imposed on firms, then the cost of production will not 
increase as estimated by the model because subsidies and the like will lower the value-added vector. In addition, these tax reductions can also increase economic efficiency (double dividend) as discussed in Chap. 13.

Thirdly, the effective carbon rate calculated in this chapter omits the feed-in tariff (FIT), which was implemented in 2009. The data used to calculate the cost increase was 2011. Thus, the burden of FIT is included in the original data. However, the volume of renewable energy has increased, leading to a higher $\mathrm{kW} / \mathrm{h}$ price increase for electricity users. The inclusion of FIT may lower the additional industry specific carbon tax needed to fill in the gap between the current effective carbon rate and the minimum effective carbon rate. This will in turn, lower the cost increase calculated in this chapter.

Finally, the effective carbon rate calculated in this chapter may be lower than predicted due to hidden and/or indirect subsidies. Subsidies can be considered as a negative carbon tax rate, which will lower the actual effective carbon rate, If this is the case, raising the effective carbon rate will increase the cost even more than shown in this chapter.

In any case, the effective carbon rate of $¥ 4,000 / \mathrm{t}-\mathrm{CO}_{2}$ is a minimum requirement to internalize the damages caused by $\mathrm{CO}_{2}$ emissions. The cost increase caused by the internalization of the externality will properly signalize the environmental impacts of the goods produced by the industries. The final demand, mainly the households, could change the consumption bundle from energy intensive goods to less energy intensive goods if the prices of goods properly presents the environmental impacts. However, the present energy related taxes have not priced carbon equally, leading to inefficient carbon reductions.

The unequal effective carbon price arises from the fear of the loss of international competitiveness. Thus, one solution is to implement an international carbon tax that assures that all internationally traded goods faces the minimum effective carbon rate of $¥ 4,000$. Then, EITE industries will at least pay the minimum carbon price even though they a given special treatment within their own country, while non-traded goods and services will face the effective carbon rate by domestic energy related taxes and the carbon tax.

Recently, the EU has restarted the discussion of implementing border tax adjustment measures for countries that do not have compatible carbon prices with the EU. The compatibility can be based on the effective carbon price or the carbon pricing gap. If the effective carbon price is used as a measure of compatibility, Japan may be penalized for not taxing EITE industries the minimum carbon price. If so, further carbon pricing within Japan may be stimulated from the threat of border adjustment measures. The border adjustment measure has not materialized, but may stimulate implementation of carbon pricing schemes in the near future. 


\section{References}

Arimura TH, Kaneko S, Managi S, Shinkuma T, Yamamoto M, Yoshida Y (2019) Political economy of voluntary approaches: a lesson from environmental policies in Japan. Econ Anal Policy 64:4153

Carbon Pricing Leadership Coalition (2017) Report of the high-level commission on carbon prices. The World Bank, Washington, D.C., May 29, 2017. Accessed 25 Dec 2019. https://www.carbon pricingleadership.org/report-of-the-highlevel-commission-on-carbon-prices/

Chuo Kankyo Shingikai (2005) Sangyo renkanhyo wo mochiita kankyozei dounyu ni yoru bukka jyosyo ni kansuru bunseki. Analysis of the Impacts of Environmental Tax Implementation on Price Increases Using the I-O Table Ministry of the Environment. Government of Japan, Tokyo, Japan

Fischer C, Fox AK (2007) Output-based allocation of emissions permits for mitigating tax and trade interactions. Land Econ 83(4):575-599

Morgenstern R, Ho M, Shih JS, Zhang X (2004) The near term impacts of carbon mitigation policies on manufacturing industries. Energy Policy 32:1825-1841

Nakamura S, Kondo Y (2004) Tansozei Donyuga Motarasu Tanki Keizaikouka no Sangyo Renkan Bunseki. Short-term economic impacts of carbon taxation using input-output analysis. Working Paper Series no. 0403. Waseda University. Tokyo, Japan, 1-21 (in Japanese)

Nansai K (2019) Embodied energy and emission intensity data for Japan using input-output tables (3EID), National Institute for Environmental Studies, Japan. http://www.cger.nies.go.jp/public ations/report/d031/index.html

Nansai K, Moriguchi Y (2012) Embodied energy and emission intensity data for Japan using inputoutput tables (3EID): For 2005 IO table, CGER, National Institute for Environmental Studies, Japan. (http://www.cger.nies.go.jp/publications/report/d031/index.html)

OECD (2016). Effective carbon rates: pricing $\mathrm{CO}_{2}$ through taxes and emissions trading systems. OECD Publishing, Paris. https://doi.org/10.1787/9789264260115-en

OECD (2018) Effective carbon rates 2018: OECD Publishing, Paris

Sato K (2016) Tanso eneruri zei no nichi doku hikaku. Comparing Japanese and German carbon and energy taxes. Chapter 2 in Kankyo zei no nichi doku hikaku. Comparing Japanese and German Environmental Taxes. Keio Gijyuku Daigaku Syuppankai (in Japanese)

Shimoda M, Watanabe T (2006) Re-examination of the scheduled carbon tax on the basis of IO analysis: a quantitative analysis on household burden by income class and by region. Shogaku Kenkyu (Aichi Gakuin University) 46(3):151-166 (in Japanese)

Sugimoto Y (1995) "An input—output analysis of carbon emission: on the effect of carbon tax and the amount of carbon embodied in tradable goods". the technical bulletin of faculty of horticulture. Chiba Univ 49:213-221 (in Japanese)

Sugino M, Arimura TH, Morita M (2012) The impact of a carbon tax on the industry and household: an input-output analysis. Environ Sci 25(2):126-133 (in Japanese)

Sugino M, Arimura TH, Morgenstern R (2013) The effects of alternative carbon mitigation policies on Japanese industries. Energy Policy 62:1254-1267

Takeda S, Arimura TH, Tamechika H, Fischer C, Fox AK (2014) Output-based allocation of emissions permits for mitigating the leakage and competitiveness issues for the Japanese economy. Environ Econ Policy Stud 16(1):89-110

Makoto Sugino is an Associate Professor of Faculty of Humanities and Social Sciences at Yamagata University in Yamagata prefecture. His research interests include climate change, energy and waste policies. He has published his research in academic journals such as, Environmental and Resource Economics, Energy Policy, and Environmental Economics and Policy Studies. Dr. Sugino holds a Ph.D. in economics from Sophia University in Tokyo, an M.Sc in economics from the Okayama University and a B.A. in Liberal Arts from International Christian University in Tokyo. He has served on an advisory committee of the local government of Yamagata. 
Open Access This chapter is licensed under the terms of the Creative Commons Attribution 4.0 International License (http://creativecommons.org/licenses/by/4.0/), which permits use, sharing, adaptation, distribution and reproduction in any medium or format, as long as you give appropriate credit to the original author(s) and the source, provide a link to the Creative Commons license and indicate if changes were made.

The images or other third party material in this chapter are included in the chapter's Creative Commons license, unless indicated otherwise in a credit line to the material. If material is not included in the chapter's Creative Commons license and your intended use is not permitted by statutory regulation or exceeds the permitted use, you will need to obtain permission directly from the copyright holder.

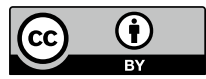

